PREPARED FOR THE U.S. DEPARTMENT OF ENERGY, UNDER CONTRACT DE-AC02-76CH03073

PPPL-3948

PPPL-3948

UC-70

Development of the Megahertz Planar Laser-induced

Fluorescence Diagnostic

for Plasma Turbulence Visualization

by

Aleksey Kuritsyn and Fred M. Levinton

April 2004

$N_{\substack{\text { PRInCETOn PLASMA } \\ \text { PHYSIES LABORATORY }}}^{D}$

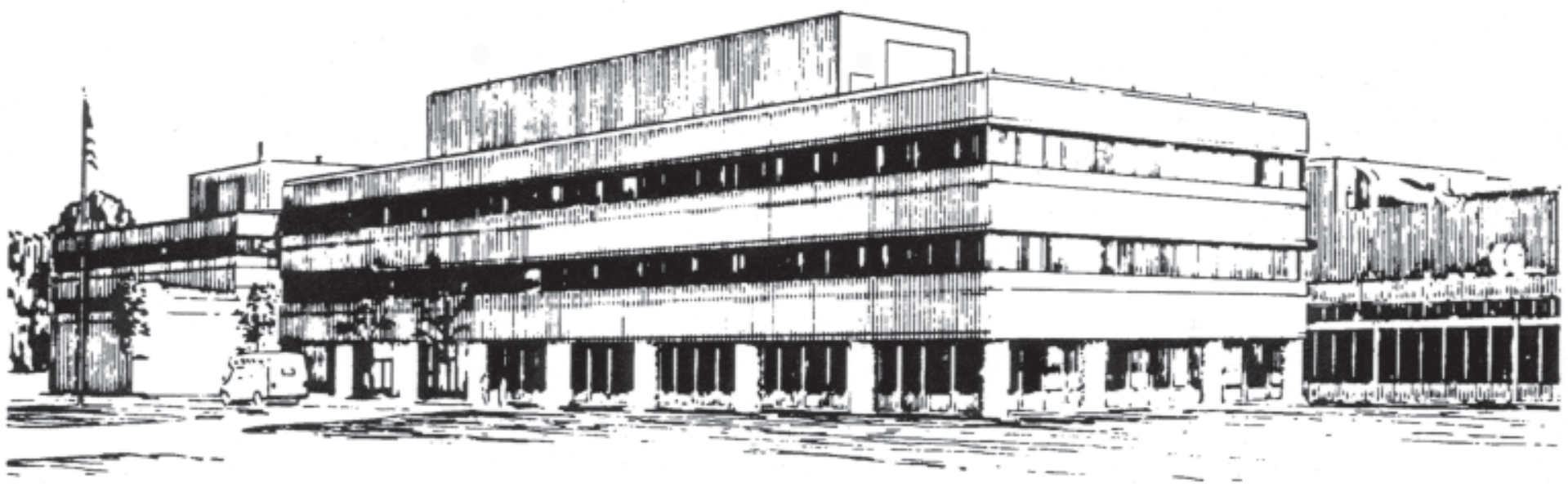

PRINCETON PLASMA PHYSICS LABORATORY PRINCETON UNIVERSITY, PRINCETON, NEW JERSEY 


\section{PPPL Reports Disclaimer}

This report was prepared as an account of work sponsored by an agency of the United States Government. Neither the United States Government nor any agency thereof, nor any of their employees, makes any warranty, express or implied, or assumes any legal liability or responsibility for the accuracy, completeness, or usefulness of any information, apparatus, product, or process disclosed, or represents that its use would not infringe privately owned rights. Reference herein to any specific commercial product, process, or service by trade name, trademark, manufacturer, or otherwise, does not necessarily constitute or imply its endorsement, recommendation, or favoring by the United States Government or any agency thereof. The views and opinions of authors expressed herein do not necessarily state or reflect those of the United States Government or any agency thereof.

\section{Availability}

This report is posted on the U.S. Department of Energy's Princeton Plasma Physics Laboratory Publications and Reports web site in Fiscal Year 2004. The home page for PPPL Reports and Publications is: http://www.pppl.gov/pub_report/

DOE and DOE Contractors can obtain copies of this report from:

U.S. Department of Energy

Office of Scientific and Technical Information

DOE Technical Information Services (DTIS)

P.O. Box 62

Oak Ridge, TN 37831

Telephone: (865) 576-8401

Fax: (865) 576-5728

Email: reports@adonis.osti.gov

This report is available to the general public from:

National Technical Information Service

U.S. Department of Commerce

5285 Port Royal Road

Springfield, VA 22161

Telephone: $1-800-553-6847$ or

(703) $605-6000$

Fax: (703) 321-8547

Internet: http://www.ntis.gov/ordering.htm 
HTPD2004-F16

\title{
Development of the Megahertz Planar Laser-Induced Fluorescence Diagnostic for Plasma Turbulence Visualization
}

\author{
Aleksey Kuritsyn* \\ Princeton Plasma Physics Laboratory, \\ Princeton University, Princeton, NJ 08543 \\ Fred M. Levinton \\ Nova Photonics Inc., Princeton, NJ 08540
}

(Dated: April 17, 2004)

\begin{abstract}
A megahertz LIF-based diagnostic system for measuring ion density fluctuations in two spatial dimensions is described. Well resolved spatial and temporal 2D images of turbulent structures will be useful in understanding ion turbulence in magnetically confined plasmas which is a key factor in the performance of fusion experimental devices. A sheet beam of a megahertz repetition rate tunable Alexandrite laser is used to excite ion emission from argon plasma. The fluorescence emitted from the plane of the laser beam is detected with a narrow band interference filter and intensified ultra-fast CCD camera providing 2D images of relative ion density fluctuations every microsecond. It is expected that the edge plasma on fusion devices will be accessible to this technique.

PACS numbers:
\end{abstract}

*Electronic address: kav@princeton.edu 


\section{INTRODUCTION}

Plasma turbulence is an important phenomenon in magnetically confined plasmas. Recent studies have shown that it has a strong impact on the performance of fusion devices - for instance, plasma edge turbulence determines the boundary values of the plasma density and temperature, which in turn affect the internal gradients and control global plasma transport [1]. Traditionally, edge turbulence in plasmas has been studied by probes or probe arrays, using two-point correlation technique, which have a drawback of perturbing the plasma. In recent years there have been few attempts to provide non-invasive twodimensional (2D) vizualization: for example, gas puff imaging diagnostic (GPI) was used to study edge turbulence in the National Spherical Torus Experiment (NSTX) and Alcator C-Mod [2, 3] and beam emission spectroscopy (BES) was employed on DIII-D [4], but those diagnostics often lack spatial resolution.

This paper describes a new megahertz planar laser-induced fluorescence (PLIF) imaging diagnostic. Nowadays, PLIF is a popular tool in the field of fluid mechanics and combustion research. This technique utilizes a laser sheet beam to excite a resonant atomic or molecular transition and subsequently image the fluorescence, usually at different wavelength, onto a high resolution 2D detector to visualize density or flow structure (Fig. 1). In plasma physics, LIF has been widely used for local measurements of ion distribution function, ion temperarure, flows, density, etc. [5] but only limited number of experiments were peformed using planar LIF $[6,7]$. A feasibility study carried out in [8] showed that the PLIF diagnostic is a promising techique for turbulent structure vizualization in plasmas of the magnetic reconnection experiment (MRX) [9] and NSTX.

Existing PLIF diagnostic systems are typically based on lasers with low repetition rate $(<100 \mathrm{~Hz})$ which is too slow to catch fast transient phenomena. Recent innovations in the design of high power solid state laser sources has resulted in the development of high repetition, high power solid state lasers such as Ruby or Nd:YAG. These lasers can generate a burst of about 100 pulses which are few microseconds apart. The described burst laser systems lack tunability and their output is limited to the first and second harmonics of Nd:YAG (1.064/0.532 $\mu \mathrm{m}$ respectively) [10] and fundamental of Ruby $(0.694 \mu \mathrm{m})[11]$ which prevents them from being used for resonant excitation. One way to achieve tunability is to couple them with the optical parametric oscillator (OPO) [12] while another approach is to 
obtain a burst from inherently tunable solid state crystals such as Alexandrite. Alexandrite has an important advantage of being easily tunable in the range $\sim 700-800 \mathrm{~nm}$ and can be efficiently frequency doubled to provide laser radiation from $\sim 350-400 \mathrm{~nm}$. This provides the flexibility to tune the laser to the resonant wavelength of the ion or atom and obtain resonant absorption of the laser radiation.

The present work is an attempt to extend the performance of a single-pulse PLIF diagnostic system which has been shown to be an effective tool for $2 \mathrm{D}$ visualization of the instabilities in a helicon plasma [7]. We applied techniques that have been developed for Ruby and Nd:YAG to build a burst megahertz repetition rate Alexandrite laser. This combined with the ultra-fast gated multi-frame 2D CCD detector can provide a real-time imaging system with microsecond resolution.

\section{BURST TUNABLE ALEXANDRITE LASER DESIGN}

The basic design of the laser is shown on Fig. 2. The overall approach of the system is to first create a single pulse having the required spectral and temporal characteristics at the fundumental harmonic ( $756 \mathrm{~nm}$ ) by a Q-switched oscillator. The pulse from the oscillator is then injected into a regenerative amplifier (Regen) that replicates this laser pulse to the desired number and temporal separation [13]. The output of this regenerative amplifier is then amplified further through three stages of laser amplification, before being up-converted to the required wavelength. A commercial tunable Q-switched Alexandrite laser from Light Age Inc. (oscillator) produces lineary polarized pulses at $10 \mathrm{~Hz}$ with duration $\sim 80$ ns and energy up to $200 \mathrm{~mJ}$ in the range $730-780 \mathrm{~nm}$. The laser incorporates a nine stage tunable birefringent filter and etalon to reduce the spectral linewidth to $0.2 \AA$ which matches the Doppler broadened absorption line of a low temperature noble gas. The pulse from the oscillator is mode-matched into the Regen ring. The Regen is a $36 \mathrm{~m}$ (120 ns optical delay) optical resonator which consists of a thin-film polarizer (TFP) used for input/output, a 27pass Herriott cell providing optical delay, a flash lamp pumped Alexandrite head, a Pockels

cell and mode matching optics. After the beam is injected its polarization is switched so that a portion of the beam is ejected by the TFP after the first pass while the reminder of the beam continues to circulate and is amplified ('regenerated') until the Pockels cell is activated next time, extracting a new portion of the beam. The train of pulses is then 
amplified to higher energy by passing through 3 amplifiers, one of which works for a double pass, and up-converted in frequency by a BBO crystal.

\section{INITIAL RESULTS AND DISCUSSION}

Typical time traces of the burst laser pulses are shown in Fig. 3. In the present configuration the number of pulses achieved is limited to the duration of the Regen free-running mode gain which was measured to be 10-15 $\mu$ s. That allows to get about 10 pulses $0.96 \mu \mathrm{s}$ apart (120 ns * 8 circulations) with the energy $\sim 2 \mathrm{~mJ} /$ pulse or 4-5 pulses $1.92 \mu$ s apart (120 ns *16) with the energy 3-4 mJ/pulse. After amplification that corresponds to less than 40 $\mathrm{mJ} /$ pulse. The main limitation to the Regen energy output is optics damage, when energy density of the laser pulse exceeds optics damage threshold. To prevent that, we had to limit the energy of the seeded pulse injected into the Regen to $15 \mathrm{~mJ}$ by putting a diaphragm into the oscillator cavity and also run the Regen amplifier at moderate gain. Conversion efficiency to the second harmonic strongly depends on the power density and for a $40 \mathrm{~mJ}$ pulse conversion efficiency was $<4 \mathrm{~mJ}$, just under $10 \%$, which is below the energy required to saturate the transition in the plasma (10 $\mathrm{mJ}$ as shown in [7]). Saturated operation is important because in this case the resulting LIF signal has a weak dependence on the local laser power density. If the Pockels cell is turned off, than the seeded pulse leaves the ring after the first pass without losing too much energy. For a $7 \mathrm{~mJ}$ output pulse from the Regen we can get $90 \mathrm{~mJ}$ at the fundamental and over $20 \mathrm{~mJ}$ in the second harmonic at $378 \mathrm{~nm}$ which means over 20\% conversion efficiency. It should be possible to achieve higher energy per pulse in the burst by improving the design of the Regen to make sure that the beam does not get focused on the mirrors. Also the burst could be further amplified by converting the single-pass amplifiers into double-pass, or improving the efficiency of the pumping heads. A factor of 2 improvement in the energy per pulse at fundamental should be enough to saturate the transition.

Initial LIF tests were performed with the single $20 \mathrm{~mJ}$ pulse in the argon plasma produced by a steady state helicon source operated at $27 \mathrm{MHz}$ [14]. The plasma column is about $2 \mathrm{~cm}$ in diameter with peak density $10^{13} \mathrm{~cm}^{-3}$, electron temperature $\sim 5 \mathrm{eV}$, magnetic field 2.5 $\mathrm{kG}$. The laser beam is transported to the plasma by a $1.5 \mathrm{~mm}$ fused silica fiber with $\sim 75 \%$ efficiency and collimated to a $2 \mathrm{~cm}$ diameter beam by a $7.5 \mathrm{~cm}$ lens. The LIF scheme for 
ArII with excitation at $378.6 \mathrm{~nm}$ was chosen. The resultant fluorescence signal was detected at $488 \mathrm{~nm}$ by the PSI-IV CCD camera system from Princeton Scientific Instruments [2, 3] equipped with a $58 \mathrm{~mm} \mathrm{f/1.2} \mathrm{Nikon} \mathrm{lens} \mathrm{and} \mathrm{a} \mathrm{narrow} \mathrm{band} \mathrm{interference} \mathrm{filter.} \mathrm{The} \mathrm{camera}$ has a frame storage capability on chip that can transfer a frame in one clock cycle and store 28 frames on the CCD chip before being read out. The shortest exposure time per frame is $1 \mu$ s. Image array size is $160 \times 80$ pixels with individual pixel size $115 \mu \mathrm{m}$.

PLIF (top) and background (bottom) emission images of plasma from adjacent CCD frames with spatial resolution of $\sim 0.8 \mathrm{~mm}$ are shown on Fig. 4 . At $1 \mu$ s exposure time LIF signal amplitude is roughly equal to the background. Since the laser pulse duration is less than 100 ns we plan to provide gating for an individual frame using an image intensifier from Hamamatsu which would improve signal to background ratio to 10:1.

Use of the gated multi-frame camera will also extend the applicability of PLIF diagnostic to high density pulsed plasma experiments $\left(\mathrm{n} \approx 10^{14} \mathrm{~cm}^{-3}\right)$ such as MRX. Initial experiments performed on MRX with a single frame camera [15] showed that the LIF signal is on the order of shot-to-shot variation of the background signal, in which case background subtraction does not work. At these densities, the laser excitation has to compete with excitation due to inelastic collsions, and the LIF signal is swamped by the collisional fluorescence background. Taking two images closely in time $(<1 \mu$ s apart), where the first image contains the superposition of LIF and background emission and the second image contains only background emission, and assuming that fluctuations of interest proceed on a time scale slower than the interframe separation time, one can recover the LIF signal by doing background subtraction.

In summary, the megahertz planar laser induced-fluorescence diagnostic for plasma turbulence vizualization is under development. Future work will include improving the performance of the burst laser to increase the energy per pulse in the burst. An image intensifier will be added to the CCD camera to provide gating for an individual frame. After the proposed upgrades, this technique combined with an argon diagnostic puff could be used for real time vizualization of the edge turbulence in fusion plasmas. 


\section{Acknowledgments}

The authors would wish to thank M. Richardson and N. Vorobiev, University of Central Florida for their help and laser development and D. DiCicco for excellent technical support. This work was supported by U.S. Department of Energy Contract No. DE-FG02-00ER83057.

[1] A. J. Wooton et al., Phys. Fluids B 2, 2879 (1990).

[2] S. J. Zweben et al., Nucl. Fusion 44, 134 (2004).

[3] R. J. Maqueda et al., Rev. Sci. Instrum 74, 2020 (2003).

[4] G. R. McKee, C. Fenzi, R. Fonk, and M. Jakubowski, Rev. Sci. Instrum. 74, 2014 (2003).

[5] K. Muraoka and M. Maeda, Plasma Phys. Control Fusion 35, 633 (1993).

[6] A. D. Bailey, R. A. Stern, and P. M. Bellan, Phys. Rev. Lett. 71, 3123 (1993).

[7] F. M. Levinton and F. Trintchouk, Rev. Sci. Instrum. 72, 898 (2001).

[8] C. H. Skinner, S. Zweben, F. M. Levinton, and J. McChesney, Rev. Sci. Instrum. 70, 917 (1999).

[9] M. Yamada et al., Phys. Plasmas 4, 1936 (1997).

[10] B. Thurow, J. Hileman, W. Lempert, and M. Samimy, Phys. Fluids 14, 3449 (2002).

[11] J. M. Grace, C. G. P. E. Nebolsine, and et al., Opt. Eng. 37, 2205 (1998).

[12] W. Lempert, N. Jiang, M. Blohm, B. Thurow, M. Samimy, G. Switzer, and L. Goss, 42nd AIAA Aerospace Sciences Meeting and Exhibit (Jan. 5-8, 2004).

[13] N. Vorobiev, M. Richardson, S. Teerawattenasook, and F. M. Levinton, 23rd CLEO, Baltimore, MD (June 1-6, 2003).

[14] S. A. Cohen, N. S. Siefert, S. Stange, R. F. Boivin, E. E. Scieme, and F. Levinton, Phys. of Plasmas 10 (2003).

[15] F. Trintchouk and F. M. Levinton (2000), unpublished data. 


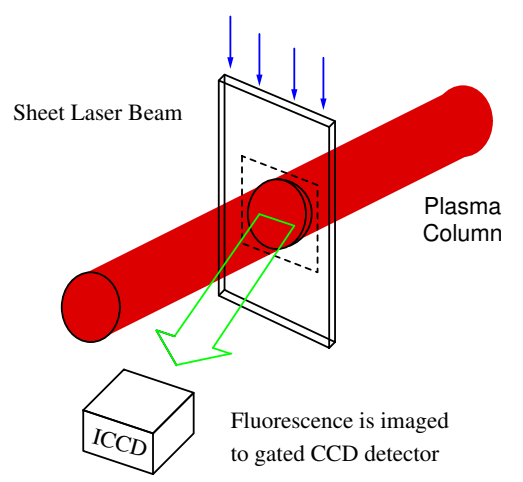

FIG. 1: Basic experimental setup for PLIF. 


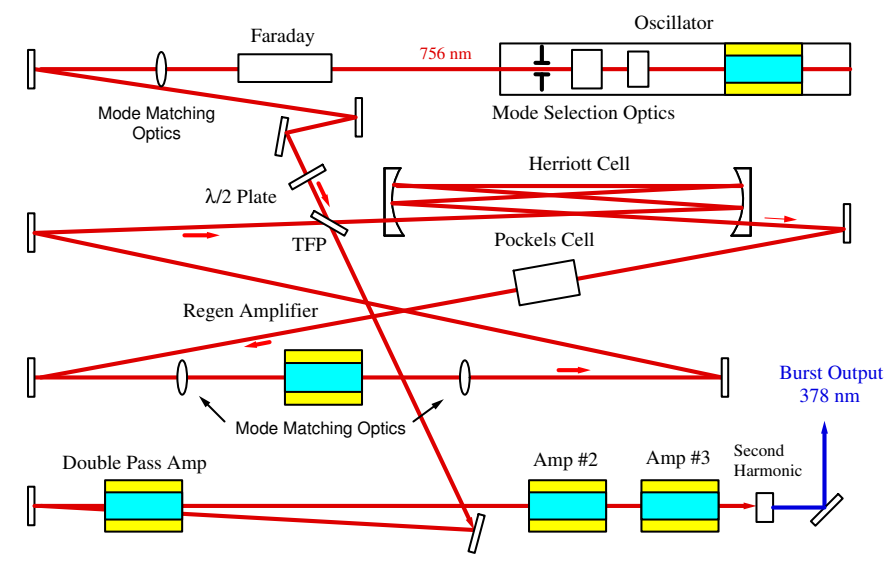

FIG. 2: Alexandrite laser system layout. 

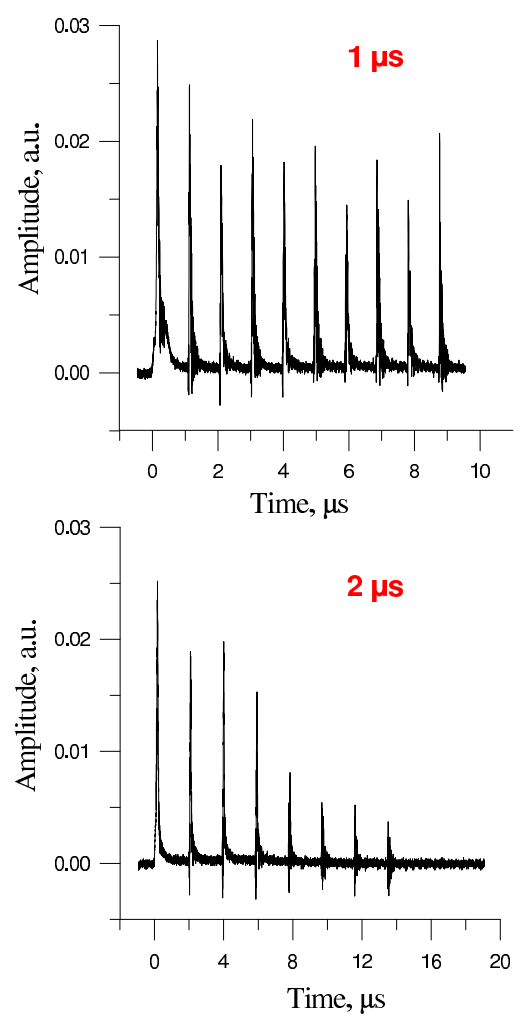

FIG. 3: Laser burst with $1 \mu \mathrm{s}$ (top) and $2 \mu \mathrm{s}$ (bottom) between pulses. 

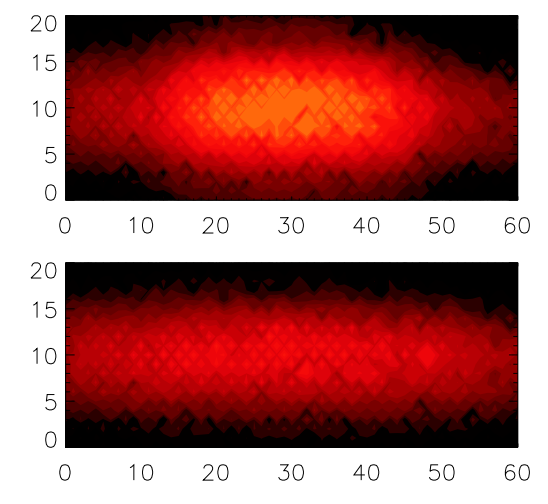

FIG. 4: Radial view of PLIF (top) and background (bottom) plasma emission. Resolution is 0.8 mm per pixel. 


\section{External Distribution}

Plasma Research Laboratory, Australian National University, Australia

Professor I.R. Jones, Flinders University, Australia

Professor João Canalle, Instituto de Fisica DEQ/IF - UERJ, Brazil

Mr. Gerson O. Ludwig, Instituto Nacional de Pesquisas, Brazil

Dr. P.H. Sakanaka, Instituto Fisica, Brazil

The Librarian, Culham Laboratory, England

Mrs. S.A. Hutchinson, JET Library, England

Professor M.N. Bussac, Ecole Polytechnique, France

Librarian, Max-Planck-Institut für Plasmaphysik, Germany

Jolan Moldvai, Reports Library, Hungarian Academy of Sciences, Central Research Institute for Physics, Hungary

Dr. P. Kaw, Institute for Plasma Research, India

Ms. P.J. Pathak, Librarian, Institute for Plasma Research, India

Ms. Clelia De Palo, Associazione EURATOM-ENEA, Italy

Dr. G. Grosso, Instituto di Fisica del Plasma, Italy

Librarian, Naka Fusion Research Establishment, JAERI, Japan

Library, Laboratory for Complex Energy Processes, Institute for Advanced Study, Kyoto University, Japan

Research Information Center, National Institute for Fusion Science, Japan

Dr. O. Mitarai, Kyushu Tokai University, Japan

Dr. Jiangang Li, Institute of Plasma Physics, Chinese Academy of Sciences, People's Republic of China

Professor Yuping Huo, School of Physical Science and Technology, People's Republic of China

Library, Academia Sinica, Institute of Plasma Physics, People's Republic of China

Librarian, Institute of Physics, Chinese Academy of Sciences, People's Republic of China

Dr. S. Mirnov, TRINITI, Troitsk, Russian Federation, Russia

Dr. V.S. Strelkov, Kurchatov Institute, Russian Federation, Russia

Professor Peter Lukac, Katedra Fyziky Plazmy MFF UK, Mlynska dolina F-2, Komenskeho Univerzita, SK-842 15 Bratislava, Slovakia

Dr. G.S. Lee, Korea Basic Science Institute, South Korea

Institute for Plasma Research, University of Maryland, USA

Librarian, Fusion Energy Division, Oak Ridge National Laboratory, USA

Librarian, Institute of Fusion Studies, University of Texas, USA

Librarian, Magnetic Fusion Program, Lawrence Livermore National Laboratory, USA

Library, General Atomics, USA

Plasma Physics Group, Fusion Energy Research Program, University of California at San Diego, USA

Plasma Physics Library, Columbia University, USA

Alkesh Punjabi, Center for Fusion Research and Training, Hampton University, USA

Dr. W.M. Stacey, Fusion Research Center, Georgia Institute of Technology, USA

Dr. John Willis, U.S. Department of Energy, Office of Fusion Energy Sciences, USA

Mr. Paul H. Wright, Indianapolis, Indiana, USA 
The Princeton Plasma Physics Laboratory is operated by Princeton University under contract with the U.S. Department of Energy.

\author{
Information Services \\ Princeton Plasma Physics Laboratory \\ P.O. Box 451 \\ Princeton, NJ 08543
}

Phone: 609-243-2750

Fax: 609-243-2751

e-mail: pppl_info@pppl.gov

Internet Address: http://www.pppl.gov 